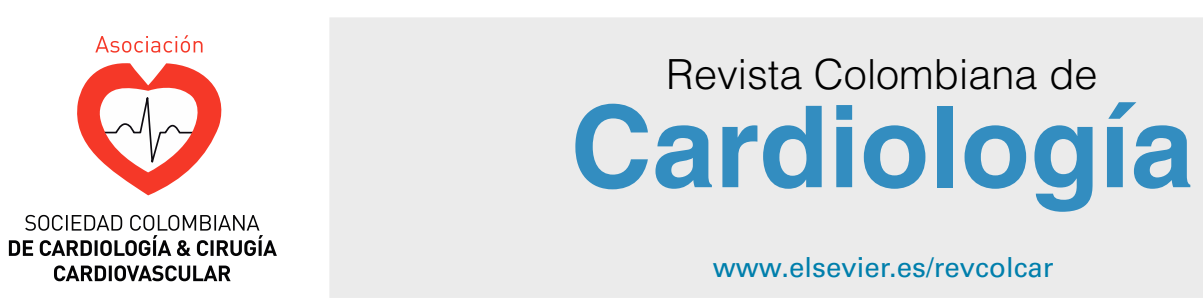

\title{
EDITORIAL
}

\section{In memoriam: Doctor Juan Karlo Urrea Zapata, Más que a un colega, adiós "al amigo"}

\section{In memoriam: Dr. Juan Karlo Urrea Zapata, Goodbye to a "friend" more than colleague}

\section{Angel Alberto García Peña}

Unidad de Cardiología. Hospital Universitario San Ignacio. Pontificia UniversidadJaveriana, Bogotá, Colombia

Recibido el 21 de julio de 2018; aceptado el 23 de julio de 2018

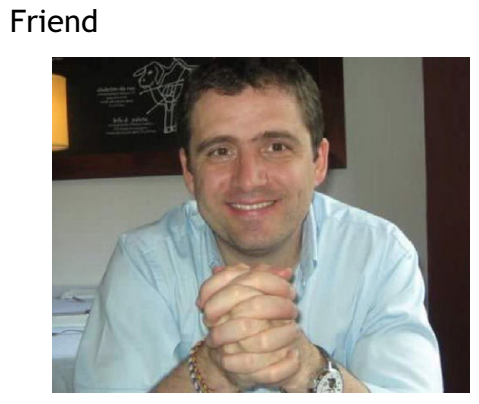

Son pocas las personas que han despertado en la Sociedad Colombiana de Cardiología y Cirugía Cardiovascular, tan grandes sentimientos de amor, apoyo, admiración y respeto. Karlo (el amigo, como le decíamos de cariño), logró demostrarnos a todos, que a pesar de la enfermedad, de las complicaciones y quizás de las injusticias de la vida, se debe mantener siempre la esperanza, las ganas de luchar y ante todo, disfrutar cada segundo con las tres cosas que él decía, eran realmente importantes en la vida: la familia, los amigos y la Cardiología.

Correo electrónico: angel.garcia@javeriana.edu.co
Karlo nació en Medellín en 1971, luego se trasladó con su familia a Cali, donde pasaría la mayor parte de su vida. Médico y Cirujano de la Universidad Libre de Cali, realizó su especialización de Medicina Interna y Cardiología en Bogotá, en la Pontificia Universidad Javeriana, donde se desempeñó posteriormente como profesor de Cardiología y Medicina Interna, hasta que el diagnóstico de su enfermedad, lo llevó de regreso con su familia a Cali, donde dirigió de forma ejemplar algunas de las más reconocidas unidades de Cardiología de la ciudad y continuó con su incesante labor docente en varias universidades.

Incansable académico, logró posicionarse en nuestra Sociedad como un gran profesional, con un perfil prometedor, que haciendo uso de su inagotable entusiasmo e ímpetu, logró convencer al presidente de la Sociedad en su momento, de crear "Actualidad Cardiológica", y más adelante, "Puesta al día en Cardiología", uno de sus grandes legados, que rápidamente se convirtió en un espacio para la discusión académica, revisiones de tema y posicionamiento crítico en aspectos relevantes del ejercicio de la Cardiología. Logró convocar a especialistas de diversos centros de mediana y alta complejidad, con el objetivo de generar diversidad, inclusión y redes de trabajo conjunto, tarea que llevó a cabalidad y con gran entereza hasta este año. Karlo 
fue destacado docente de varias universidades, investigador y conferencista, lo que le permitió compartir sus conocimientos en múltiples escenarios. Sus publicaciones, videos educativos y presentaciones nos seguirán acompañando por mucho tiempo.

Podría extenderme con una detallada descripción de sus virtudes académicas, habilidades clínicas y docentes; sin embargo, tuve la fortuna de ser uno de sus mejores amigos y haber compartido con él, en las cosas que creía, eran realmente importantes. Pocos conocen los detalles de su enfermedad, la cual descubrimos por bromas y sarcasmos entre amigos. Por fortuna, eso le permitió quedarse "dando lora' un rato más en esta vida. Me quedan los recuerdos de nuestras conversaciones y discusiones académicas, pero sin duda, más allá de los aspectos de la vida profesional y académica que muchos tuvimos el privilegio de compartir, el regalo que nos dio fue la oportunidad y el placer de conocer, disfrutar y aprender de un ser humano excepcional, de comportamiento intachable, reconocido por el trato humano, sensible y desinteresado, pero sobretodo, por la desbordante alegría y entusiasmo con los que lograba llevar a cabo todo lo que se proponía. En una de las últimas conversaciones que tuvimos, recuerdo sus palabras: "Amigo, parece que me queda poco, se me están acabando las fuerzas...', y en lugar de continuar con lo que hubiese podido ser una triste conversación, presagio de su despedida, se convirtió en un cátedra de gratitud con la vida, de esperanza, de lucha permanente y de ejemplo a seguir. Una muestra del desbordante amor por su esposa Claudia, sus hijos, su familia y sus amigos. Sin rencor con la vida, como quien tiene total certeza que la vida sigue del otro lado, que luego habrá momento para encontrarnos nuevamente, se despidió de forma usual, fraternal y cariñoso, no sin antes recordarme los artículos que estábamos escribiendo, las tareas pendientes y el "in press" que debía leerme. Hoy solo es un adiós. Seguro nos encontraremos más adelante.

A Claudia, Isabella, Sebastián, y a toda su familia, en nombre de todos mis colegas, amigos, y de la Revista Colombiana de Cardiología, nuestras más sinceras condolencias y nuestro apoyo y compromiso en estos difíciles momentos. Estén seguros que seguiremos las enseñanzas de vida y cardiología que Karlo nos dejó. 